\section{BIBLIOGRAPHY}

BRUUSGaARD, E. (1929), Arch.f. Derm. u. Syph., 157, 309. CURTIS, A. C., KRUSE, W. T., and NORTON, D. H. (1949), Am. F. of Syph. Gonor. E Ven. Dis., 33, 527.

DATTNER, B. (I944), 'The Management of Neurosyphilis,' Grune \& Stratton, New York.

DATTNER, B. (1949), Am. F. Syph. Gonor. \& Ven. Dis., 33, 571. DATTNER, B. (1950), Am. F. Syph. Gonor. E Ven. Dis., 34, 373. DATTNER, B., and THOMAS, E. W. (1942), Am. F. Syph. Gonor. $E^{\circ}$ Ven. Dis., 26, 21.

DELAY, DESCLAUX and STEVENIN (1947), Rev. Neur., July, $5 \times 5$.

FARMER, T. W. (1948), צ.A.M.A., 138, 48.

HAHN, R. D. with assistance of LEWIS, B., WIGGALL, R. H., and CROSS, E. S. (1951), Am. F. Syph. Gonor: E Ven. Dis., 35, 433.

HEYMAN, A., SHELDON, W. A., and EVANS, L. D. (1952), Brit. F. Ven. Dis., 28, 50.

JONES, R. W., HEYMAN, A., SMITH, W. A., and WILSON, R. (1951), Am. F. Syph. Gonor. E Ven. Dis., 35, 72.

KIERLAND, R. R., and O'LEARY, P. A. (1950), Am. F. Syph. Gonor. \& Ven. Dis., 34, 443 .

KIERLAND, R. R., O'LEARY, P. A., and UNDERWOOD, L. J. (1948), Am. F. Syph. Gonor. E' Ven. Dis., 32, 470. KLAUDER, J. V., and GROSS, B. A. (1949), Am. F. Syph. Gonor.
\& Ven. Dis., 33, 234.
KOPP, T., ROSE, A. S., and SOLOMON, H. C. (1948), Am. F. Syph. Gonor. 'E Ven. Dis., 32, 509.

KOTEEN, H. (1949), Am. F. Syph. Gonor. \& Ven. Dis., 33, 364. LANGE, C., and HARRIS, A. H. (1944), Am. F. Pub. Health, $34,1087$.

LEREBOULLET, J., and BRISSET (1949), Rev. Neur., 8, 646. LEREBOULLET, J., and JALLOUSTRE, S. (1947), Bull. Soc. Med. Hop., 26, 775.

LESCHER, G., and RICHARDS (1947), Brit. Med. F., ii, 565.

MOORE, J. E. (1946), 'Penicillin in Syphilis,' Blackwell, Oxford.

NICOL, W. D., and WHELEN, M. (1951), Brit. F. Ven. Dis., 27, 132.

PERLO, V. P., ROSE, A. S., CARMEN, L. R., and SOLOMON, H. C. (195I), Am. F. Syph. Gonor. E' Ven. Dis., 35, 559.

PUTKONEN, T., and REHTIJARVI, K. (195I), Acta. DermatVenereol., 31, 120.

RAVAUT, P. A. (1903), An. de Dermat et Syph., 4, 537.

REDMOND, A., NICOL, C. S., and SHOOTER, R. A. (1952), Brit. Ұ. Ven. Dis., 28, 13.

ROBINSON, R. C. V. (1952), Brit. F. Ven. Dis., 28, 80.

ROMANSKY, M. J., OLANSKY, S., TAGGART, S. R., LAWDMAN, G.' S., and ROBIN, E. D. (1951), Am. 'F. Syph. Gonor. Es Ven. Dis., 35, 234.

ROSAHN, P. (1946), fournal of V.D. Information Supplement 21.

THOMPSON, R. G., and PRESTON, R. H. (1950), Am. F. Syph. Gonor. E' Ven. Dis., 34, 356.

\title{
FRACTURES AROUND THE ELBOW JOINT IN CHILDREN
}

\author{
By A. W. Lipmann Kessel \\ London
}

The swings and slides of public parks provide our hospitals with a regular week-end clientèle of small boys who have sustained fractures about the elbow joint. The diagnosis of many such fractures calls for nice judgment and a meticulous attention to the general principles as well as the details of treatment. The 1935 Report of the B.M.A. Committee on Fractures did not analyze fractures in children, but if it is true that the average incapacity period for a simple fracture of the clavicle in adults who were not treated in an organized clinic was 22 weeks, as compared to five weeks for those treated in organized clinics, it would be a fair assumption that a similar analysis for the group of more serious and difficult fractures we are now considering would reveal an even greater difference.

Diagnosis and classification. The precise diagnosis of the type of fracture is essential, but by no means always easy because of the complexity of the ossification of the lower end of the growing humerus. Leaving aside for the moment the question of soft tissue damage, this group of fractu res may be broadly classified into five radiological types. Intermediate as well as complex types will, of course, occur. In cases of doubt the opposite elbow must always be X-rayed for comparison:

Supracondylar fractures-extension and flexion varieties.

Transcondylar-simple and ' $T$ '-shaped.

Epicondylar avulsion, with or without dislocation.

Fracture-separation of the external condyle epiphysis.

Fracture of the head or neck of the radius.

Treatment. Each type of fracture will be considered separately, but there are certain general principles applicable to the treatment of all these fractures.

I. Manipulative reduction must always be gentle. Only too often does a complication arise from the violence of attempted reduction rather than from the original injury itself.

2. Wherever possible a 'single attack' should be made to achieve reduction by closed manipulation. It should be carried out under general anaesthesia with $\mathrm{X}$-ray control (not screening), and the several attempts that may be necessary to achieve satisfactory alignment should be carried out at the same session. An examination of some of the disasters which have occurred shows only 
too commonly that there has been a series of manipulations on succeeding days by a succession of people up the hierarchy-from Casualty Officer, House Surgeon, Registrar to Consultant.

3. The decision for or against an open reduction should be made at the beginning of treatment and not as a last resort after several attempts at manipulation have failed. Efforts to avoid an unnecessary open operation on a child's elbow must be matched by a firm and early decision to operate when indicated.

4. As is now well known, injudicious attempts to speed the restoration of full movement of the elbow joint is fraught with dangers, and no passive movement, massage or joint stretching should be permitted.

Complications. I. Of the injury itself: damage to the brachial artery and median and ulnar nerves.

2. During early treatment: damage to brachial artery or median nerve by violence in manipulation; venous obstruction due to an incompletely reduced fracture; excessive elbow flexion or too tight splintage; excessive new bone formation around the joint following repeated manipulations or forced movement.

4. Late complications: Imperfect reduction may cause a deformity of the elbow which will be accentuated by subsequent growth. This deformity may give rise to mechanical trouble in the joint or may cause damage to the ulnar nerve.

Prognosis. It is as well to remember that normal growth will do wonders by remodelling the bone, but cannot compensate for serious soft tissue injury.

The prognosis depends primarily on the quality of treatment. The B.M.A. Committee on Fractures previously quoted, reported that of 132 cases of fracture of the scaphoid treated in fracture clinics only 2 were permanently incapacitated, whereas of 65 cases not treated in organized clinics

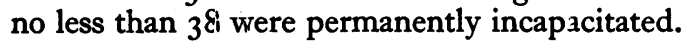

\section{Analysis of Various Fractures}

I. Supracondylar fracture. This is the commonest injury around the elbow joint and its diagnosis should present no difficulty. The typical fracture is caused by an extension injury and the fracture line runs obliquely from behind downwards and forwards. When there is any significant displacement the small lower frugment is displaced backwards and upwards and is extended on the upper fragment. There is usu llly an added rotational or lateral displacement. This displacement may cause the sharp lower end of the upper fragment to damage the brachial artery or median nerve.
Treatment. If there is any significant degree displacement the child must be admitted to hospital and the fracture dealt with by forma manipulative reduction under general anaesthesiawith X-ray control. The technique of manipula-s? tion can only be taught by precept in practice. AO full description is given in all textbooks and willo not be repeated here, but it usually suggests that ${ }^{\overline{\bar{T}}}$. the initial traction should be applied to the fully-西 extended arm. It is safer to apply steady axialo traction in the direction in which the forearm is lying. During such traction the lower fragment is $\vec{\circ}$ flexed forwards in an attempt to lock the fragments. $\vec{\omega}$ Rotational and lateral displacements should be corrected at the same time. The arm is placed in as much flexion as is possible without occluding? the radial pulse and immobilized by a plasterif backslab with a crepe bandage over wool and $a_{\omega}^{0}$ collar-and-cuff sling. The bandaging should N allow regular palpation of the radial pulse andic inspection and movement of the fingers. In the ${ }_{\circ}^{\omega}$ less common variety of supracondylar fracture which occurs as a result of a flexion injury, the ${ }_{C}$ fracture line runs obliquely downwards and backwards, so that the lower fragment may be dis- $\frac{\mathrm{C}}{\mathrm{D}}$ placed forwards. This fracture is stable in the extended position, but the elbow joint may be $\overrightarrow{0}$ partly flexed after a week or two without disturbiog the line of fracture. This lessens the discomfot: and complications resulting from prolonged ir mobilization of a fully-extended elbow joint.

2. Transcondylar fracture. The fracture line runs transversely across the lower cartilaginous $\mathbb{D}$ end of the humerus and may extend ' $T$ '-shaped $\stackrel{\circ}{\vec{T}}$ into the joint. In children this fracture is usually $\overrightarrow{\vec{O}}$ mpacted and its diagnosis will be difficult unless a lateral X-ray of the normal elbow is taken for comparison. Subsequent growth will not com-

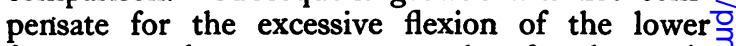
fragment and an attempt must therefore be made to correct the angular deformity by manipula- -3 . tive reduction into the fully-extended position.

3. Epicondylar avulsion. This results from a severe valgus or varus injury and is commonly 응 complicated by dislocation of the joint. Although the X-ray evidence of bone damage may be음 minimal, examin ttion usually shows considerable lateral instability due to soft tissue damage.

(a) External epicondylar avulsion. This consists $N$ essentially of avulsion of the origin of the extensor ${ }_{\omega}^{N}$ muscles and the external collateral ligament of the elbow joint. The bony damage is of little or noo importance. Three to four weeks' immobilization $\frac{}{\Phi}$ in a comfortable plaster splint with the elbow at $\stackrel{\oplus}{?}$ $r$.ght angles and including the wrist joint is all 0 that is necessary. For gross tears in older children it may on occasion be advisable to suture the $\stackrel{\Omega}{\Omega}$ 


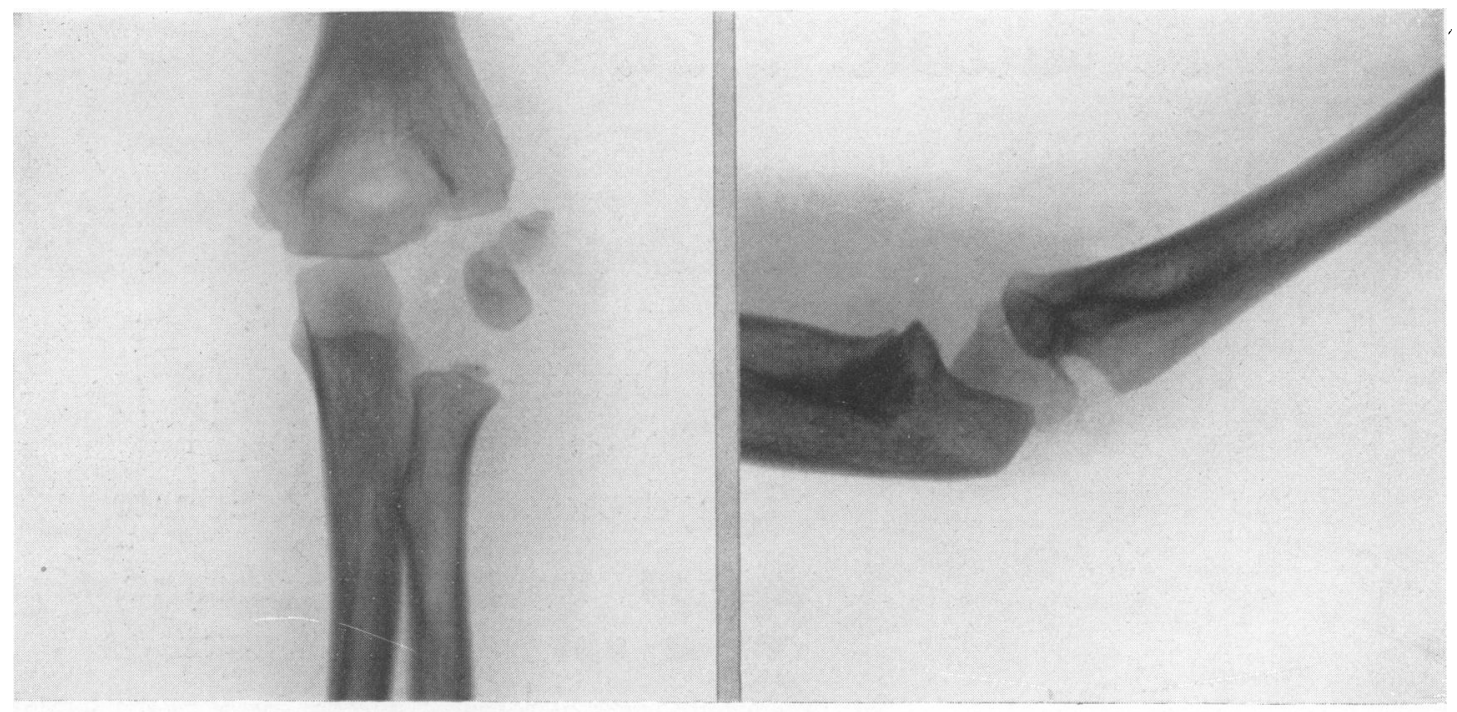

Antero-posterior view.

Lateral view.

FIG. 1.-Fracture-separation of the external condyle epiphysis. The typical fully-established displacemente is shown. The forejoint consists of a large block of cartilage with its radio-opaque orsific centres. Boy, aged 6 years.

epicondyle and attached muscle origin back into place in order to reduce lateral instability.

(b) Internal epicondylar avulsion. This is a more serious injury in which soft tissue damage is again of paramount importance. Complete avulsion of the internal epicondyle with its attached flexor muscle origin and collateral ligament results in considerable instability of the joint. There may be immediate damage to the ulnar nerve, and this is particularly to be expected when the fragment is displaced into the elbow joint dragging the nerve along with it. Although manipulative reduction of such a displaced fragment is occasionally successful (and a method is described in which a faradic contraction of the flexor muscles is used to augment the manipulation), it is doubtful whether this method should be employed other than in exceptional circumstances, particularly if there is evidence of ulnar nerve damage. Even if the fragment is manipulated out of the joint, it still requires open operation to fix the fragment back into position. According to the degree of damage to the ulnar nerve, and the experience of the surgeon, it may be found desirable to do an anterior transposition of the nerve at the same time. The initial injury to the ulnar nerve is usually a lesion in continuity and full recovery may be expected to occur.

4. Fracture-separation of the external condyle epiphysis. This fracture is a juxta-epiphyseal injury of the principal epiphysis at the lower end of the humerus. The displacement is due to direction of the initial force of injury outwards a upwards, and may be accompanied by a displacément due to contraction of the common extensor muscles of the forearm, which causes an outward rotation of up to 180 degrees, with or without added axial rotation of 90 degrees. The degree of displacement may also be related to the position of the fracture line in relation to the origin of the 3 radial extensors.

In spite of the considerable interest in this injury? and the attention which has been paid to it, itso treatment is not yet generally understood. Wilson 1 . speaking from the experiences of a large fracture clinic in New York said in 1936 , 'Judging by the

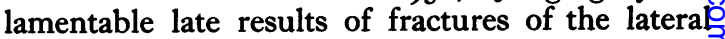
condyle of the humerus in children, which we encounter each year in our orthopaedic clinic, we? may say without charge of unfairness that the medical profession has failed as yet to grasp the importance of this pathological lesion.'

In the same year, Buxton ${ }^{2}$ gave a very clear" account of this fracture and laid down generaf principles of treatment which, if followed, wouldw undoubtedly prevent the "lamentable late re? sults' of which Philip Wilson wrote. Buxtore gave this accurate description of the fracture. 'The fragment consists of the capitellar epiphysis (i.e., the capitellum and half the trochlea) and a flake of the diaphysis, usually of the back of the lower end of the shaft.' His advice on treatment? 


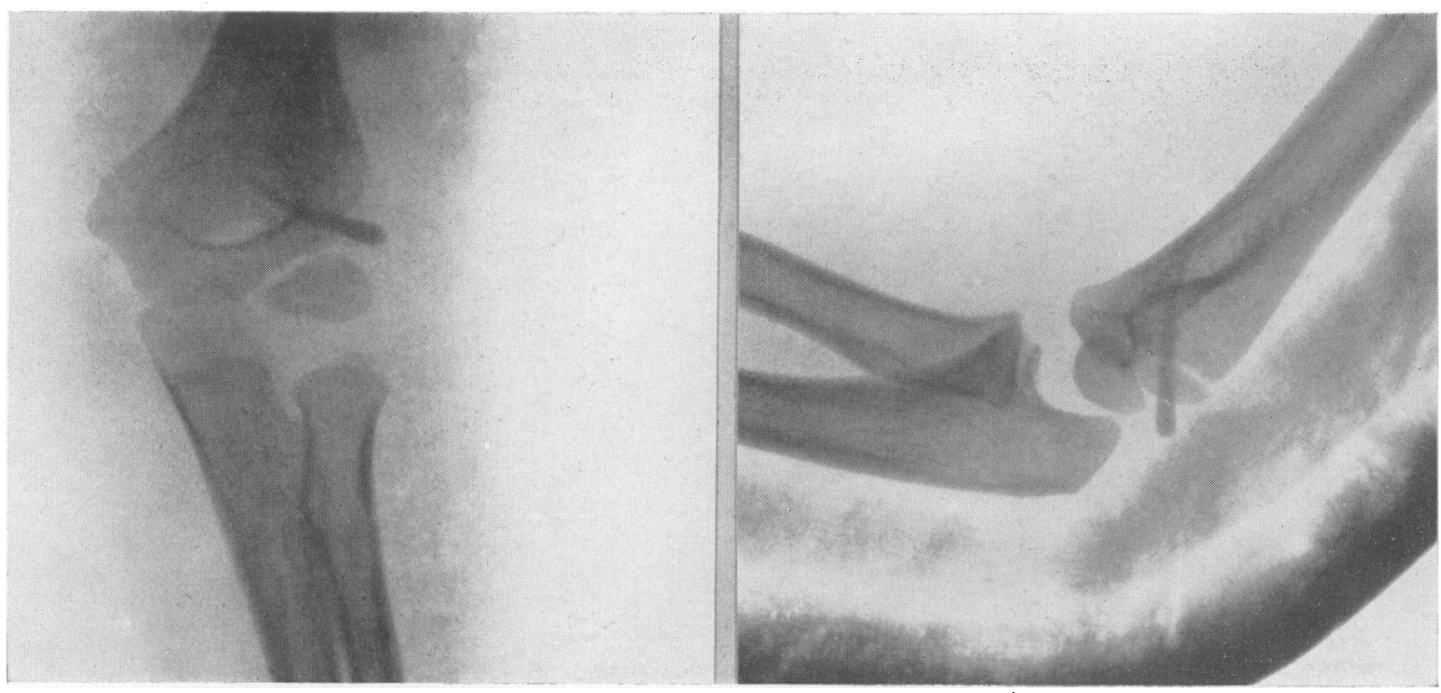

FIG. 2.-Operative reduction within 24 hours of injury. A single beef-bore peg has been used. A single suture or temporary steel pins are probably better methods of internal fixation.

was equally precise: 'If there is no, or little, displacement-simple splintage; if there is displacement-open re-position is employed, or non-union witl cubitus valgus will occur.'

Almost every observer who has made a special study of this fracture concludes that non-union is characteristic in cases with any significant displacement which have been treated conservatively. It is obvious that this is very different from what happens to supracondylar fractures where nonunion practically never occurs and closed manipulation is almost always the best line of treatment. As Brewster and Karp ${ }^{3}$ indicate: - This failure to appreciate the difference between external condylar and supracondylar fractures can result only in disaster to the patient and discomforture to the surgeon.' Speed and Macey ${ }^{4}$ draw the interesting parallel between these fractures and fractures of the femoral neck. They say that " the distinction between condylar and supracondylar fractures of the humerus is just as vital for a true understanding of the problems involved in their treatment, as that between central fractures of the neck of the femur and trochanteric fractures.'

The important points about this injury may be summarized as follows:(I) Radiology. (a) True antero-posterior and lateral films of both elbows must be taken. (b) The apparently small fragment really consists of a large block of cartilage with small radio-opaque ossific centres. (c) The anteroposterior view must be carefully studied for the degree of displacement and rotation of the frag- ment. (2) Treatment. If there is (a) little or no displacement-simple splintage in a position of comfort. (b) displacement without rotation-an attempt to correct this by manipulative reduction is advised in standard textbooks and may be worth while. Non-union of the fragment is a definite danger. (c) rotation of the fragmentoperative replacement with minimum damage to soft tissue attachments and internal fixation by suture or metal peg (Fig. 2). The detached fragment must never be excised. (3) Late complications are the result of non-union, which leads to: (a) Mechanical derangement of the joint with consequent degenerative arthritis in adult life. (b) Cubitus valgus and consequent tardy ulnar paresis (Fig. 3).

5. Fracture of the head and neck of the radius. (a) Fracture of the head of the radius. In children the equivalent to the adult type of compression fracture of the radial head is a juxta-epiphyseal fracture which causes the radial head to tilt and be pushed off in varying degree from the neck. Occasionally the whole of the radial head is completely separated. (b) Greenstick fracture of the neck of the radius. This occurs as a result of the same type of injury and causes an angulation of the neck of the radius. The deformity may be observed by rotation of the forearm and when in doubt it is advisable to take radiographs in varying degrees of pronation and supination (Fig. 4). Treatment. Even though the angular deformity may appear to be minimal, accurate realignment is essential because future growth will increase 


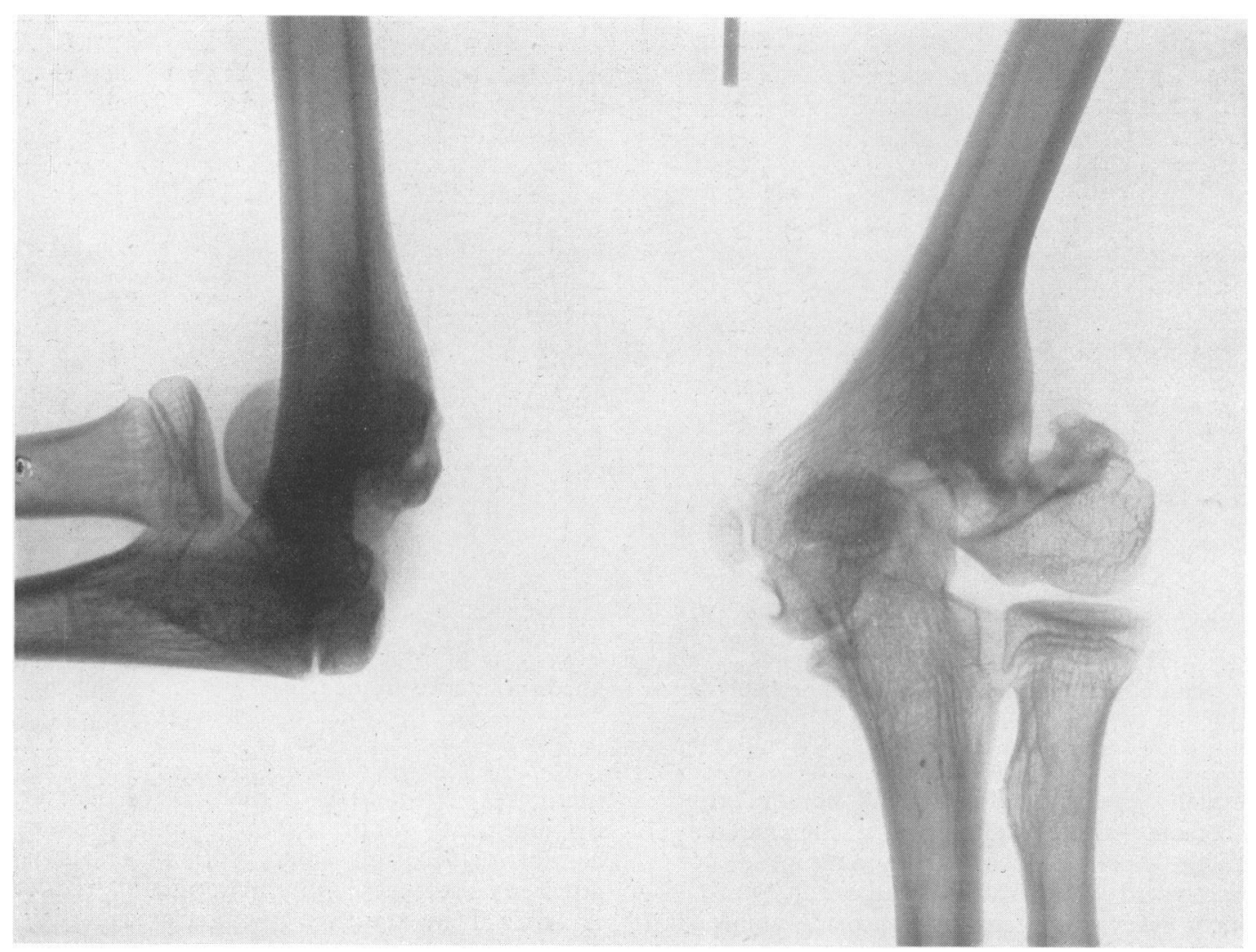

Fig. 3.-Boy, aged 13. Typical end result of the fracture if bony union has not been achieved by accurate reposition and fixation. Cubitus valgus is already evident and this will increase.

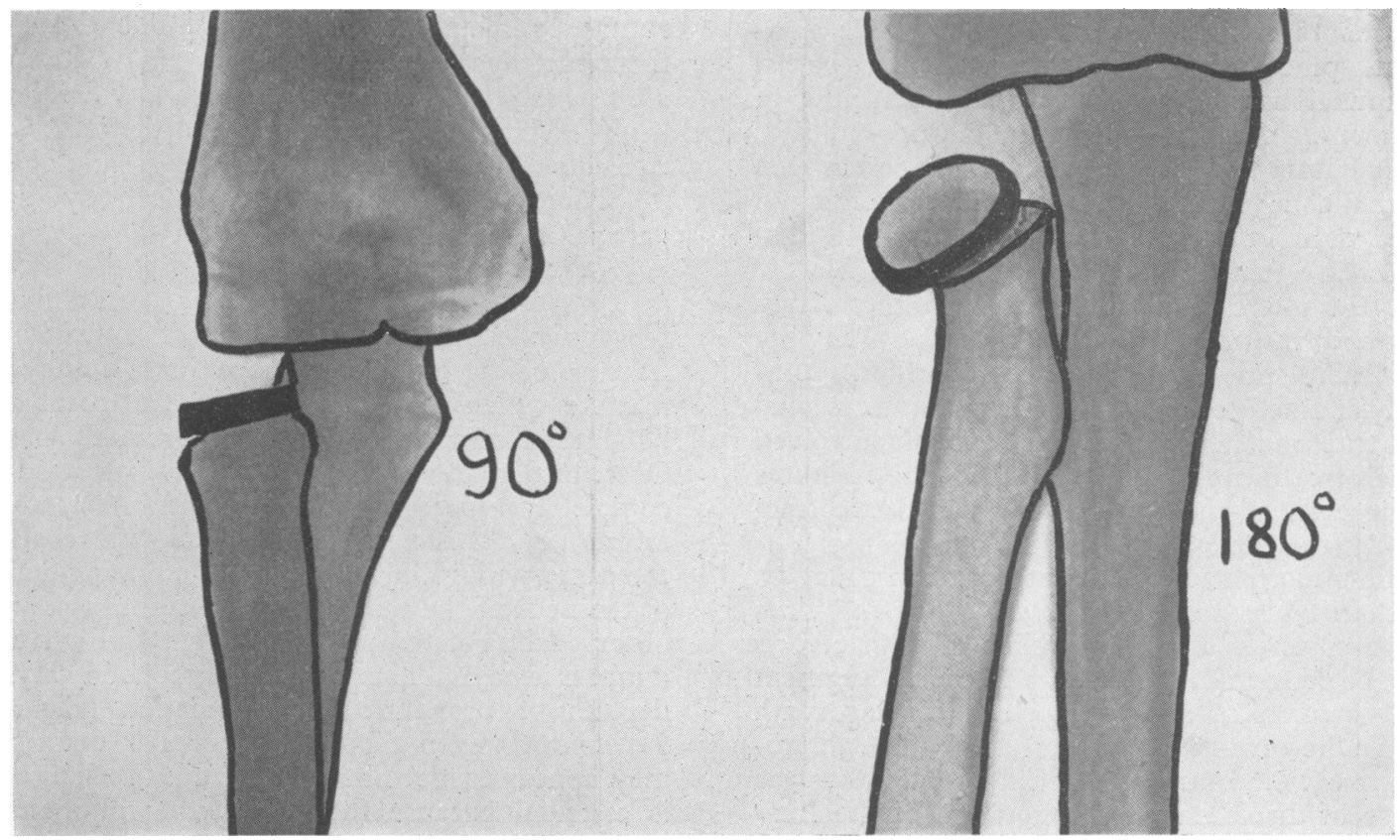

Fig. 4. - To show how the anatomy of an upper radial fracture is disclosed by taking radiographs in varying degrees of rotation of the forearm (after Jeffery). 


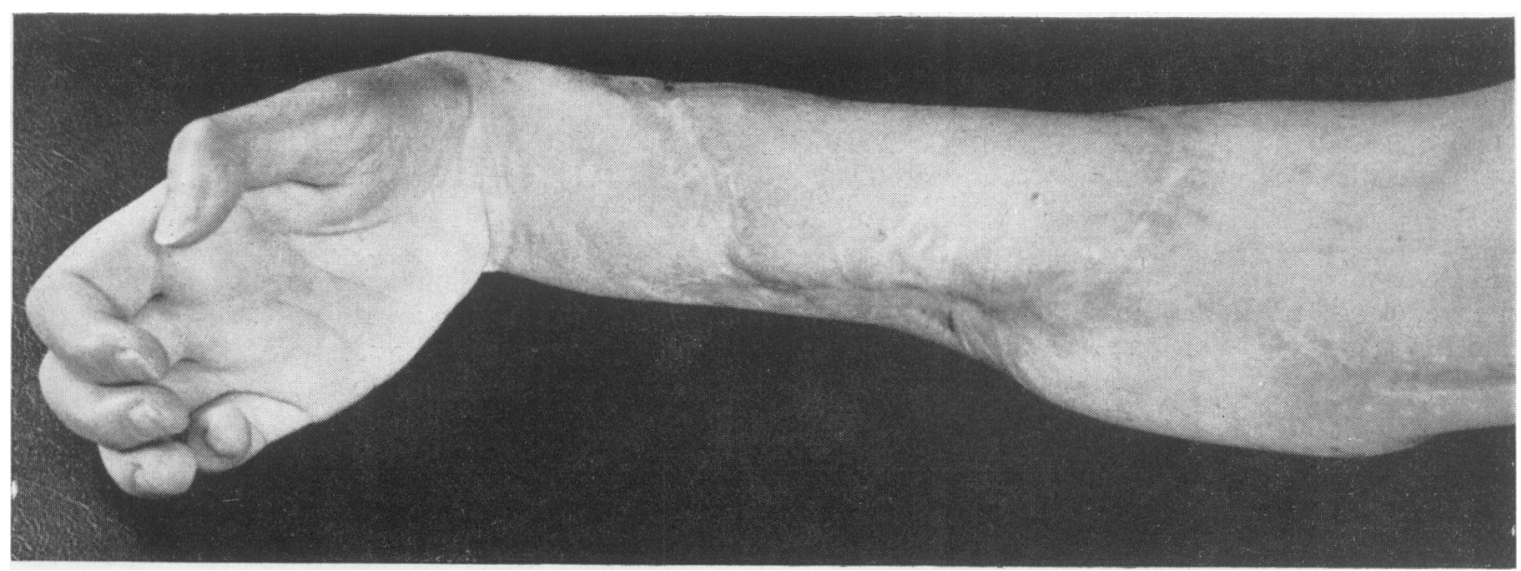

FIG. 5.-The calamity of ischaemic contracture. Salvaging operations can improve, but never restore normal function.

rather than diminish any existing deformity and may result in a subluxation of the upper end of the radius. The standard method of treatment is manipulative reduction by direct pressure at open operation. No internal fixation is necessary. Recently a method of checking the precise line of angulation and consequent correction of the deformity by closed manipulation has been described by Jeffery ${ }^{5}$. This is a method which may well come into general use, but at present is probably too specialized for everyday practice.

\section{Special Complications}

Both traumatic ossification and Volkmann's ischaemia may occur at any site in an injured limb and at any age, but they are most common as a complication of a fracture or dislocation of the elbow in childhood.

Traumatic ossification. In the early weeks after injury a vague rounded shadow appears in the radiographs extending widely into the soft tissues around the fracture. The shadow becomes more dense and takes on the appearance of new bone. Although many fanciful explanations have been advanced to account for this development, there is little doubt that it is due to stripping of the periosteum in combination with the fracture haematoma. ${ }^{6}$ The extent of the final mass of new bone will depend on the management of the case. With care the ossifying haematoma will shrink in size as it becomes more dense and will end up as a small well-defined mass extending from the fracture line into the muscle. The complication is best prevented by prompt, accurate and gentle reduction of the displaced bone with its attached periosteum. Similarly the prohibition of passive stretching in the early weeks after injury will prevent a re-displacement of the periosteum and further haemorrhage. If the warning shadow should become visible in the X-rays, the arm must be put to rest; first by splintage, then with a simple collar-and-cuff sling until serial X-rays show clear-cut evidence of shrinkage and definition of the new bone. Guarded active use may be permitted after the acute phase, lasting about two to three weeks, has passed. It may take as long as 12 months before final consolidation in the residual mass has occurred. Any attempt to remove or 'disperse' the ossifying haematoma before final consolidation, will inevitably aggravate the condition.

Volkmann's ischaemic contracture (Fig. 5). This dreaded complication follows-as Volkmann himself said over 70 years ago-' a continuous stoppage of the arterial blood.' 7 The brachial artery is damaged by the fracture fragments, usually the sharp lower end of the humeral shaft in a supracondylar fracture. The obstruction to the flow is due to injury of the brachial artery with resultant segmental spasm of the main vessel and one or more of its branches and collateral vessels. Tight splints, excessive flexion of the elbow, or an incompletely reduced fracture cause venous obstruction which will aggravate the obstruction of the arterial flow. The arteries to the flexor muscles of the forearm are virtually end-arteries ${ }^{8}$ and early necrosis will occur as in any other organ deprived of its blood supply. In course of time the infarcted areas are replaced by fibrous tissue. The main nerves, which usually escape direct injury at the elbow, may be damaged by ischaemia which, in some cases, leads to degeneration along the entire length of the nerve trunk.

Immediate treatment of ischaemia or threatened ischaemia. The policy of 'wait and see' has no place in the management of threatened circulatory failure in an injured limb. There is hourly danger of irreparable damage and even the loss of the 
limb. Lloyd Griffiths ${ }^{\theta}$ has put forward a plan of management in such an emergency which lays considerable stress on the general systemic care of the patient. He proposes: (i) A detailed circulatory investigation of the patient, including haemoglobin, blood count, blood pressure and coagulation time. (ii) Appropriate resuscitation. (iii) Removal of all external pressure at the fracture site. (iv) A direct attempt to alleviate the obstruction by operation. This consists of manipulative reduction of any displacement, after which the hand is observed in the operating theatre. If the circulation does not return after a few minutes the brachial artery is widely exposed and mobilized. It is repaired by suture whenever possible, or arterectomy is carried out for irreparable local damage. If the spasm of the vessel persists, some attempt must be made to overcome it. It is not yet established whether the spasm is due to sympathetic nerve stimulation or direct stimulation of the arterial wall. All means must therefore be taken to overcome it. Sympathetic paralysis may be brought about by one or a combination of several means-brachial plexus block, novocaine injection of the adventitia of the artery, periarterial stripping or the use of a general autonomic blocking agent such as hexamethonium bromide (C6) given intramuscularly. The most efficient drug to paralyze the arterial muscle is a locally applied solution of $2 \frac{1}{2}$ per cent. papaverine sulphate. ${ }^{10}$

\section{Summary}

A classification of the main types of fractures $\frac{3}{\frac{1}{2}}$ around the elbow joint of a child and a brief $c$. description of the causes and management of the principal early complications are given.

Unlike almost every other fracture in a child, 음 a fracture around the elbow joint may lead to흠 joint stiffness, serious permanent disability or $\frac{\bar{D}}{\widehat{D}}$ complications arising in adult life.

The diagnosis must be precise and should be controlled by X-rays of the opposite limb for suspected fracture of the lower end of the humerus and by $\mathrm{X}$-rays in varying degree of rotation of the forearm $\vec{\omega}$ for suspected fracture of the upper end of the $\frac{\text { ? }}{8}$ radius.

Treatment must be carried out promptly with 3 . all available in-patient facilities. Decision to carry out open operation should be made on the initial study of the fracture and not forced by a $v$ series of failed manipulations.

\section{REFERENCES}

1. WILSON, D. (1936), Ұ. Bone छ $\mathscr{7 t}$. Surg., 18, 301.

2. BUXTON, ST. J. D. (1936), Brit. Med. $\mathscr{f} ., 2,665$.

3. BREWSTER, A. H., and KARP, M. (1940), S.G.O., 71, 643. ֻ

4. SPEED, J. S., and MACEY, H. B. (1933), F. Bone. छ $\mathfrak{f} t$. Surg., 15, 903.

5. JEFFERY, C. C. (1950), Ұ. Bone \&ீ भt. Surg., 32b, 314.

6. WATSON-JONES, R. (1943), 'Fractures and Joint fojuries,' Livingstone, Edinburgh, 3rd edition, 495 .

7. VOLKMANN, R. VON (1881), Zbl. Chir., 8, 801 (reprinted F. Int. Chir., 1938, 3, 77).

8. NISBET, N. W. (1952), Э. Bone \& Yt. Surg., 34b, 245.

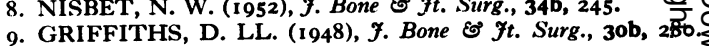

10. KINMONTH, J. B. (1952), Brit. Med. F., i, 59.

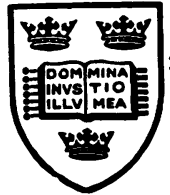

\title{
OXFORD MEDICAL PUBLICATIONS
}

\section{THE DIAGNOSIS AND TREATMENT OF INTRATHORACIC NEW GROWTHS}

\author{
By MAURICE DA VIDSON, D.M., F.R.C.P.
}

With a Chapter on Radiotherapy by David W. Smithers, M.D., M.R.C.P., D.M.R. and a Chapter on Operative Treatment by Oswald S. TUB BS, F.R.C.S.

\begin{abstract}
' Comprehensive and authoritative but not unduly specialized. It is clearly meant to inform the non-specialist seeking information rather than to be a complete specialist presentation.'

-British Journal of Surgery.
\end{abstract}

- Has a comprehensiveness and authority because it is backed up by clinical acumen and experience -a most useful book for the practitioner at the present time.'-Medical Press.

'The book is written essentially from a common-sense standpoint.'-The Lancet.

268 pages.

172 illustrations.

42s. net. 